\title{
Serological biomarkers of hepatocellular carcinoma in Egyptian patients
}

\author{
Sarmad F. El-Tayeh ${ }^{\mathrm{a}}$, Tarek D. Hussein ${ }^{\mathrm{a}}$, Motawa E. El-Houseini ${ }^{\mathrm{b}}$, Mahmoud A. Amer ${ }^{\mathrm{a}}$, \\ Mamdooh El-Sherbinic and Wael M. Elshemey, ${ }^{\mathrm{d}, *}$ \\ ${ }^{a}$ Zoology Department, Faculty of Science, Cairo University, Cairo, Egypt \\ ${ }^{\mathrm{b}}$ Cancer Biology Department, NCI, Cairo University, Cairo, Egypt \\ ${ }^{\mathrm{c}}$ Med. Oncology Department, NCI, Cairo University, Cairo, Egypt \\ ${ }^{\mathrm{d}}$ Biophysics Department, Faculty of Science, Cairo University, Cairo, Egypt
}

\begin{abstract}
Hepatocellular carcinoma (HCC) is one of the most aggressive cancers worldwide. In Egypt, the disease is usually detected in an advanced stage at which no treatment may be effective including surgery. Early detection of the disease is thus an important goal allowing the patient to be treated before the enlargement of the tumor or its metastasis to distant organs. Tumor markers are serological agents which serum level may be useful in predicting the presence of the tumor at early stages. Alpha fetoprotein (AFP) which is the golden marker for HCC is of low sensitivity, therefore, additional markers such as alphaL-fucosidase (AFU), transforming growth factors alpha and beta (TGF- $\alpha$ and TGF- $\beta$ ) and interleukin- 8 (IL- 8 ) are suggested to be simultaneously evaluated in order to enhance the detection of HCC. A total of 96 patients with different liver diseases such as $\mathrm{HCC}$, hepatitis $\mathrm{C}$ virus (HCV), hepatitis B virus (HBV) and cirrhotic patients are included in this study. Sixteen healthy volunteers are used as a control group. In patients with HCC each of AFP, AFU, TGF- $\alpha$ and TGF- $\beta$ recorded significantly higher levels than the other patient groups and controls. HCC patients recorded significantly lower level of IL- 8 compared to the other patient groups but significantly higher than the control. For AFP, AFU, TGF- $\alpha$, TGF- $\beta$ and IL- 8 , at the optimal cut-off values (obtained from the receiver operating characteristic (ROC) curves), the calculated sensitivities are 46\%, 72.97\%, 67.56\%, 54.05\% and $83.8 \%$, respectively. The simultaneous evaluation using all of the suggested markers resulted in increasing the sensitivity up to $100 \%$. It thus recommended that, if patients with cirrhosis, as high risk patients, are subjected to regular examination using these markers in addition to AFP, HCC may be detected by $100 \%$ sensitivity in an early stage and as a consequence an effective treatment can be achieved.
\end{abstract}

Keywords: AFP, AFU, TGF- $\alpha$, TGF- $\beta$, IL-8, HCC, HCV, biomarkers

\section{Introduction}

Hepatocellular carcinoma (HCC) is a major health problem worldwide because of its constantly increasing incidence in developed countries and its poor prognosis [1-4]. Early detection is important in the management of this type of cancer [5]. Only minorities (30\% to $40 \%$ ) of patients are early diagnosed and are eligible for the most effective treatment. Nevertheless, even in these cases the prognosis and survival are not satis-

*Corresponding author. E-mail: waelelshemey@yahoo.com. factory because the recurrence rate is higher than $70 \%$ at 5 years after resection, and the currently available therapies have failed to reduce this rate $[6,7]$.

Several tumor markers have been shown to be diagnostic for HCC. They can be classified into two major categories: First:- sensitive molecular markers [4] which include hepatoma specific alpha fetoprotein (HSAFP) and AFP-mRNA [8], hepatoma specific gammaglutayl transferase [9], transforming growth factor alpha and beta [4], insulin-like growth factor-II (IGF-II) and its mRNA [10] and heat shock protein (HSP) [11]. The second category includes serological markers such as AFP [12], alpha-L-fucosidase (AFU) [13,14], anti- 
p53 antibody [15], serum des-gamma-carboxy prothrombin (DCP) [16] and others [17]. Transforming growth factors alpha and beta (TGF- $\alpha$ and TGF- $\beta$ ) and interleukin-8 (IL-8) are suggested serological markers to be investigated in the present study.

The primary marker for HCC is $\alpha$-fetoprotein (AFP), a single polypeptide chain glycoprotein produced by the fetal yolk sac and liver with molecular weight of around $70 \mathrm{kDa}$. Its level falls rapidly to less than $10 \mathrm{ng} /$ $\mathrm{mL}$ immediately after birth, but in certain pathological conditions it rises again. Pathological elevation of AFP is seen in hepatocyte regeneration, hepatocarcinogenesis and embryonic carcinomas. It has a reported sensitivity of $39 \%$ to $65 \%$ for the detection of HCC [2,12, 15].

Alpha-L-fucosidase (AFU) is a lysosomal glycosidase found in all mammalian cells and is concerned with the degradation of a variety of fucose-containing glyco-conjugates [18]. Higher activities of the enzyme were detected in HCC patients $[13,19,20]$. Furthermore, the persistently elevated AFU level in patients with cirrhosis adds to the detection of $\mathrm{HCC}$ at an earlier stage [20] owing to elevated activity of AFU at least 6 months before the detection of HCC by ultrasonography in $85 \%$ of patients [13].

IL-8 is a multifunctional CXC chemokine that affects human neutrophil functions, including chemotaxis, enzyme release, and expression of surface adhesion molecules. IL- 8 is produced by a wide variety of cell types, including monocytes, neutrophils, fibroblasts, and endothelial cells $[21,22]$. IL-8 was identified to be an angiogenesis-regulating molecule that induces angiogenesis. The expression of IL-8 has been found in various human cancers [23]. Various studies have demonstrated that IL-8 regulates tumor cell growth and metastasis in melanoma [24], carcinoma of breast [25], stomach, pancreas and liver [26,27]. Akiba et al. [27], provided evidence that IL- 8 produced by HCC is an angiogenic factor of HCC. Therefore, it is of interest to elucidate the role of serum IL- 8 as a biological tumor marker in HCC patients. Very little work was done to clarify the role of IL-8 in early detection of HCC in Egyptian patients.

Transforming growth factor-alpha (TGF- $\alpha$ ) is a potent mitogen of normal and neoplastic hepatocytes. It has been reported to play a pivotal role in hepatocarcinogenesis [28]. TGF- $\beta 1$ is highly expressed in the biological fluids of HCC patients. It is a pleiotropic growth factor that correlates with a worse prognosis and shorter survival [29-31]. Fransvea et al. [32] have shown that TGF- $\beta 1$ induced a more aggressive pheno- type of HCC cells by decreasing the expression levels of E-cadherin. In HCC, TGF- $\beta 1$ triggers migration and invasion of surrounding tissues $[33,34]$. Statistically significantly higher levels of TGF- $\beta 1$ have been measured in the serum of patients with gastric cancer and venous invasion as compared with those without blood vessel involvement [35]. No articles related to measuring TGF- $\alpha$ in Egyptian patients are present until now.

The aim of the present work is to study a battery of tumor markers of $\mathrm{HCC}$ in Egyptian patients including AFP, AFU, TGF- $\alpha$, TGF- $\beta$ and IL- 8 . The study aims also to clarify the possible inter-correlations between these markers and their correlations with the clinicopathological findings of patients with HCC. The simultaneous determination of all these markers may enhance an early detection of $\mathrm{HCC}$ where the patient may have a successful treatment at an early stage before metastasis or enlargement of the tumor. Since AFP is the current golden marker for the detection of HCC, therefore, the other markers are combined to AFP in order to improve its low sensitivity.

\section{Patients and methods}

\section{Patients}

Samples taken during routine follow-up of 96 patients with different liver diseases are utilized in the current study. They included 37 patients with HCC, 28 patients with liver cirrhosis (all infected by HCV), 21 patients with $\mathrm{HCV}, 10$ patients with $\mathrm{HBV}$ in addition to 16 healthy volunteers. Serum samples of the patients and controls were obtained and stored at $-80^{\circ} \mathrm{C}$ until used.

\subsection{Materials and method}

Blood samples are collected at the National Cancer Institute (NCI) of Cairo during a period of 6 months. Patients are diagnosed according to radiological imaging, laboratory tests, and clinical investigations following the institutional protocol. Blood samples are collected using vein puncture technique in glass test tubes and are left to clot for a period of 30 minutes at $37^{\circ} \mathrm{C}$. Samples are then centrifuged at $3000 \mathrm{rpm}$ for $10 \mathrm{~min}-$ utes. The supernatant sera are collected and stored at $-63^{\circ} \mathrm{C}$. All samples are studied following the completion of the collection period. However, AFU enzyme activity is assayed within 30 days after collection because the enzyme would be affected after this period. 
Table 1

Major characteristics of the patients groups and the control

\begin{tabular}{lcccc}
\hline Group & Number & M/F & Median age (yrs) & Range \\
\hline HCC & 37 & $29 / 8$ & 55 & $41-70$ \\
Cirrhosis & 28 & $22 / 6$ & 49 & $42-62$ \\
HCV & 21 & $13 / 8$ & 47 & $35-64$ \\
HBV & 10 & $10 / 0$ & 46 & $30-55$ \\
Control & 16 & $11 / 5$ & 46 & $35-59$ \\
\hline
\end{tabular}

\section{Methods}

AFP is determined using commercially available microparticle enzyme immunoassay. AFP is expressed in $\mathrm{ng} / \mathrm{ml}$. AFU activity is measured by enzyme degradation of an artificial substrate (p-nitrophenyl alpha -Lfucopyranoside). The liberated p-nitophenol is detected by colorimetric reaction and measured at $450 \mathrm{~nm}$. The enzyme activity is measured as nanomoles of p-nitrophenyl cleaved per $1 \mathrm{ml}$ of serum per hour $(\mathrm{nmol} / \mathrm{ml} / \mathrm{hr}$ ). TGF- $\alpha$, TGF- $\beta$ and IL- 8 are measured in the serum of patients and controls using commercially available ELISA kits, according to the instructions of the manufacturer.

\subsection{Statistical analysis}

The SPSS version 15 is used in data analysis. Data are expressed as mean \pm standard deviation. Abnormally distributed data are transformed (log transformation) before analysis. One way ANOVA and independent sample t-test are used to compare the means of the variables in the different groups. Correlation between the variables is calculated using Pearson's product moment correlation coefficient. Receiver operating characteristic (ROC) curves are plotted in order to determine the best cut-off values of the studied markers.

The following formulae are used in ROC analysis [36]:-

Sensitivity $=a /(a+c)$, Specificity $=d /(b+d)$, Diagnostic accuracy $=(a+d) /(a+b+c+d)$, Positive predictive value $=a /(a+b)$, Negative predictive value $=$ $c /(c+d)$ and Differential positive rate $=$ sensitivity $(\%)$ $+\operatorname{specificity}(\%)-1$.

Where:- $a=$ true positive cases, $c=$ false negative cases, $d=$ true negative cases, $b=$ false positive cases.

\section{Results}

\subsection{Study population}

The present study is performed on a total of $96 \mathrm{pa}-$ tients with different liver diseases and 16 adult volun-
Table 2

Liver function tests in the patients groups and the control

\begin{tabular}{lccc}
\hline Group & AST (U/L) & ALT (U/L) & Albunim $(\mathrm{g} / \mathrm{dl})$ \\
\hline HCC & $87.75 \pm 38.37 \mathrm{a}$ & $74.94 \pm 47.29 \mathrm{a}$ & $2.81 \pm 0.41 \mathrm{c}$ \\
Cirrhosis & $92.71 \pm 63.43 \mathrm{a}$ & $71.85 \pm 46.71 \mathrm{a}$ & $3.40 \pm 0.40 \mathrm{~b}$ \\
HCV & $74.42 \pm 28.69 \mathrm{a}$ & $72.19 \pm 38.88 \mathrm{a}$ & $3.36 \pm 0.33 \mathrm{~b}$ \\
HBV & $31.30 \pm 7.73 \mathrm{~b}$ & $34.80 \pm 17.64 \mathrm{~b}$ & $3.54 \pm 0.32 \mathrm{~b}$ \\
Control & $25.12 \pm 9.70 \mathrm{~b}$ & $26.50 \pm 12.01 \mathrm{~b}$ & $3.97 \pm 0.33 \mathrm{a}$ \\
F-ratio & $\mathrm{F}=10.84$, & $\mathrm{F}=5.89$, & $\mathrm{F}=30.02$, \\
p-value & $p<0.001$ & $p<0.001$ & $p<0.001$ \\
\hline
\end{tabular}

The different letters indicate significantly different means according to Duncan's multiple range test.

teers. Table 1 shows the major characteristics of the patients and controls including the numbers, the ratio of males to females as well as the age of the patients given as median and range.

\subsection{Liver function tests}

AST, ALT and albumin are measured in patient groups and controls. For AST and ALT, there is a significant difference between the patient groups and control as evaluated by ANOVA test $(p<0.001)$. Patients with HCC, cirrhosis and HCV showed significantly higher levels of AST and ALT compared to both the HBV group and the control. HBV and control showed non-significant difference between each other. For albumin, the lowest level was recorded for HCC group $(2.81 \pm 0.41 \mathrm{~g} / \mathrm{dl})$ and the highest for the control group $(3.97 \pm 0.33 \mathrm{~g} / \mathrm{dl})$ whereas the other three groups came in between and the difference between them was non-significant (Table 2).

\subsection{Marker levels in the patient groups and control}

Table 3 shows that significantly different levels of AFP, AFU, TGF- $\alpha$, TGF- $\beta$ and IL- 8 are detected in most of the patient groups compared to control as evaluated by ANOVA test ( $p<0.001$ in all). For AFP, the HCC group patients showed the highest level of all groups $(987.37 \pm 2585.18 \mathrm{ng} / \mathrm{ml})$ whereas the HCV and HBV patient groups and control showed non-significantly different values. For AFU, the HCC group showed the highest enzyme activity of all groups $(581.62 \pm 386.94 \mathrm{nmol} / \mathrm{ml} / \mathrm{hr})$. No significant difference can be detected between the other groups and the control. With respect to TGF- $\alpha$, the HCC group showed a level of $345.32 \pm 347.44 \mathrm{pg} / \mathrm{ml}$ which is significantly higher than the cirrhosis, HBV and the control group but not significantly different from the HCV group. For TGF- $\beta$, the HCC group showed the highest level $(303.45 \pm 229.46 \mathrm{pg} / \mathrm{ml})$ whereas the oth- 
Table 3

AFP, AFU, TGF- $\alpha$ TGF- $\beta$ and IL- 8 mean levels in the patients groups and the control

\begin{tabular}{lccccc}
\hline Group & AFP(ng/ml) & AFU $(\mathrm{nmol} / \mathrm{ml} / \mathrm{hr})$ & TGF- $\alpha(\mathrm{pg} / \mathrm{ml})$ & TGF- $\beta(\mathrm{pg} / \mathrm{ml})$ & $\mathrm{IL}-8(\mathrm{pg} / \mathrm{ml})$ \\
\hline HCC & $987.37 \pm 2585.18 \mathbf{a}$ & $581.62 \pm 386.94 \mathbf{a}$ & $345.32 \pm 347.44 \mathbf{a}$ & $303.45 \pm 229.46 \mathbf{a}$ & $181.35 \pm 93.05 \mathbf{b}$ \\
Cirrhosis & $28.03 \pm 35.92 \mathbf{b}$ & $208.27 \pm 101.66 \mathbf{b}$ & $118.85 \pm 94.98 \mathbf{b c}$ & $129.82 \pm 92.77 \mathbf{b}$ & $475.17 \pm 583.95 \mathbf{a}$ \\
HCV & $23.67 \pm 45.95 \mathbf{b c}$ & $125.66 \pm 44.25 \mathbf{b}$ & $157.78 \pm 86.97 \mathbf{a b}$ & $175.14 \pm 158.97 \mathbf{b}$ & $396.14 \pm 441.41 \mathbf{a}$ \\
HBV & $19.00 \pm 30.17 \mathbf{b c}$ & $278.65 \pm 79.00 \mathbf{b}$ & $90.50 \pm 74.69 \mathbf{c}$ & $111.7 \pm 75.23 \mathbf{b}$ & $313.00 \pm 137.08 \mathbf{a b}$ \\
Control & $3.21 \pm 2.65 \mathbf{c}$ & $152.67 \pm 50.99 \mathbf{b}$ & $75.12 \pm 48.08 \mathbf{c}$ & $88.35 \pm 46.25 \mathbf{b}$ & $59.91 \pm 18.8 \mathbf{c}$ \\
F-ratio, & $\mathrm{F}=12.42$, & $\mathrm{F}=19.07$, & $\mathrm{F}=9.34$, & $\mathrm{F}=7.96$, & $\mathrm{F}=12.64$, \\
p-value & $p<0.001$ & $p<0.001$ & $p<0.001$ & $p<0.001$ & $p<0.001$ \\
\hline
\end{tabular}

The different letters indicate significant different means according to Duncan's multiple range test.

Table 4

Correlations between the studied makers and the liver function test

\begin{tabular}{lccccc}
\hline & AFP & AFU & TGF- $\alpha$ & TGF- $\beta$ & IL-8 \\
\hline AFP & 1 & 0.383 & -0.034 & 0.007 & 0.105 \\
AFU & & 1 & $0.332^{*}$ & 0.181 & 0.256 \\
TGF- $\alpha$ & & & 1 & 0.070 & -0.101 \\
TGF- $\beta$ & & & & 1 & $0.545^{* *}$ \\
IL-8 & & & & & 1 \\
ALT & 0.318 & 0.078 & -0.192 & -0.006 & 0.091 \\
AST & -0.061 & -0.134 & 0.063 & 0.111 & -0.001 \\
Albumin & -0.058 & -0.179 & 0.025 & -0.134 & -0.22 \\
\hline
\end{tabular}

${ }^{*}$ significant correlation at $p<0.05 .{ }^{* *}$ significant correlation at $p<$ 0.01 .

er groups were comparable. IL-8 was quite different where the HCC group showed the lowest level (181.35 $\pm 93.05 \mathrm{pg} / \mathrm{ml}$ ) in all of the patient groups but still significantly higher than the control group. The other three groups showed more or less comparable nonsignificant values.

\subsection{Correlations between the studied makers and the liver function test}

Table 4 shows the correlations between the studied makers and each other as well as their correlation with the liver function test. Significant correlation can be detected in two cases only; between AFU and TGF- $\alpha$, $r=0.322, p<0.05)$ also between IL-8 and TGF- $\beta$, $r=0.545, p<0.01)$.

\subsection{Correlation between the clinicopathological features and the studied markers}

Table 5 shows the correlation between the clinicopathological features and the studied markers. With respect to the tumor size, TGF- $\beta$ and IL- 8 are significantly correlated to the tumor size where patients with tumor size more than $5 \mathrm{~cm}$ recorded significantly ( $p<$ 0.001 for both) higher values $(468.05 \pm 197.63 \mathrm{pg} / \mathrm{ml}$ and $230.89 \pm 95.18 \mathrm{pg} / \mathrm{ml}$ for TGF- $\beta$ and IL-8, respectively) than those with tumor size less than $5 \mathrm{~cm}$
$(129.72 \pm 88.93 \mathrm{pg} / \mathrm{ml}$ and $129.06 \pm 55.73 \mathrm{pg} / \mathrm{ml}$, respectively).

The same markers (TGF- $\beta$ and IL-8) are also correlated to the stage $(p<0.001$ and $<0.01$, respectively) of the tumor where the tumor level increases as the stage increases. On the other hand, none of the studied markers is correlated to the tumor grade $(p>0.05$ in all).

\subsection{Sensitivity and specificity of the studied markers solely and in combination}

Table 6 shows the sensitivity, specificity, diagnostic accuracy, positive and negative predictive values and the differential positive rate (DPR) of AFP, AFU, TGF$\alpha$, TGF- $\beta$ and IL- 8 at the optimal selected cut-off values. Serum AFP (Fig. 1) recorded a low sensitivity (46\%) and a high specificity $(96 \%)$ with a moderate diagnostic accuracy of $68 \%$. The positive and negative predictive values and the DPR were $94 \%, 42.5 \%$ and $42.4 \%$, respectively. For AFU enzyme (Fig. 2), the sensitivity is better than AFP (73\%) and the specificity is good $(89 \%)$ with a diagnostic accuracy of $80 \%$. The positive and negative predictive values and the DPR were $90 \%, 28.6 \%$ and $62.3 \%$, respectively. A more or less similar values are recorded for both TGF- $\alpha$ (Fig. 3) and TGF- $\beta$ (Fig. 4). IL-8 (Fig. 5), recorded the highest sensitivity $(83.8 \%)$ of all the markers with a specificity of $64.3 \%$ and diagnostic accuracy of $75.4 \%$. The positive and negative predictive values and the DPR were $75.6 \%, 25 \%$ and $48.1 \%$, respectively.

The simultaneous determination of the markers increased the sensitivity gradually up to $100 \%$. When AFU results are combined to that of AFP, the sensitivity increased from $46 \%$ for AFP alone to $83.4 \%$ for both markers. The addition of TGF- $\alpha$ increased the sensitivity to $91.9 \%$; and the value increased to $97.3 \%$ by the addition of TGF- $\beta$. Finally a combined detection using the results of all markers including that of IL-8 increased the sensitivity to $100 \%$ (Fig. 6). 
Table 5

Correlation between the clinicopathological features and the studied markers

\begin{tabular}{|c|c|c|c|c|c|c|}
\hline & AFP & AFU & TGF- $\alpha$ & TGF- $\beta$ & IL-8 & \\
\hline \multirow[t]{3}{*}{ Tumor size } & $<5 \mathrm{~cm}$ & $1614.84 \pm 3449.08$ & $513.17 \pm 336.12$ & $318.94 \pm 290.98$ & $129.72 \pm 88.93$ & $129.06 \pm 55.73$ \\
\hline & $>5 \mathrm{~cm}$ & $392.92 \pm 1168.05$ & $646.46 \pm 428.52$ & $370.31 \pm 400.13$ & $468.05 \pm 197.63$ & $230.89 \pm 95.18$ \\
\hline & p-value & 0.153 & 0.301 & 0.659 & 0.001 & 0.001 \\
\hline \multirow[t]{5}{*}{ Tumor stage } & $\mathrm{I}(n=7)$ & $1282.15 \pm 3046.19$ & $608.01 \pm 373.00$ & $283.42 \pm 241.50$ & $106.71 \pm 61.22 \mathrm{a}$ & $92.00 \pm 34.07 \mathrm{a}$ \\
\hline & $\mathrm{II}(n=11)$ & $292.92 \pm 595.26$ & $410.09 \pm 315.21$ & $328.81 \pm 300.9$ & $242.54 \pm 210.53 \mathrm{ab}$ & $130.00 \pm 42.40 \mathrm{a}$ \\
\hline & III $(n=9)$ & $1503.13 \pm 4034.73$ & $688.87 \pm 447.55$ & $344.00 \pm 372.05$ & $357.88 \pm 235.52 b c$ & $204.55 \pm 55.51 b$ \\
\hline & $\mathrm{IV}(n=10)$ & $1080.73 \pm 2179.40$ & $655.31 \pm 404.55$ & $408.00 \pm 461.15$ & $459.20 \pm 212.15 \mathrm{c}$ & $279.50 \pm 91.93 c$ \\
\hline & p-value & 0.970 & 0.361 & 0.911 & 0.007 & 0.001 \\
\hline \multirow[t]{4}{*}{ Tumor grade } & $\mathrm{I}(n=9)$ & $1692.75 \pm 4012.41$ & $585.35 \pm 418.80$ & $484.66 \pm 515.91$ & $346.88 \pm 222.33$ & $187.00 \pm 88.21$ \\
\hline & $\mathrm{II}(n=13)$ & $497.93 \pm 1411.25$ & $626.30 \pm 327.95$ & $312.15 \pm 320.94$ & $316.07 \pm 218.21$ & $159.84 \pm 88.81$ \\
\hline & $\mathrm{III}(n=15)$ & $988.32 \pm 2395.03$ & $540.66 \pm 434.67$ & $290.46 \pm 230.86$ & $266.46 \pm 252.00$ & $196.00 \pm 101.78$ \\
\hline & p-value & 0.787 & 0.850 & 0.390 & 0.699 & 0.581 \\
\hline
\end{tabular}

The different letters indicate significant different means according to Duncan's multiple range test.

Table 6

Sensitivity, specificity, diagnostic accuracy, positive and negative predictive values and differential positive rate of AFP, AFU, TGF- $\alpha$, TGF- $\beta$ and IL-8 at the optimal selected cut-off values

\begin{tabular}{|c|c|c|c|c|c|c|c|}
\hline Marker & Cut-off & Sensitivity & Specificity & Diagnostic accuracy & $\begin{array}{c}\text { Positive } \\
\text { predictive value }\end{array}$ & $\begin{array}{c}\text { Negative } \\
\text { predictive value }\end{array}$ & $\begin{array}{l}\text { Differential } \\
\text { positive rate }\end{array}$ \\
\hline AFP & 112.75 & 45.94 & 96.42 & 67.69 & 94.44 & 42.55 & 42.37 \\
\hline AFU & 347.40 & 72.97 & 89.28 & 80.00 & 90.00 & 28.57 & 62.25 \\
\hline TGF- $\alpha$ & 156.00 & 67.56 & 82.14 & 73.84 & 83.33 & 34.28 & 49.71 \\
\hline TGF- $\beta$ & 212.00 & 54.05 & 89.28 & 69.23 & 86.95 & 40.47 & 43.33 \\
\hline IL-8 & 252.00 & 83.80 & 64.30 & 75.40 & 75.62 & 24.97 & 48.10 \\
\hline $\mathrm{AFP}$ or $\mathrm{AFU}$ & & 83.78 & 100 & 90.76 & 100 & 17.64 & 83.78 \\
\hline AFP, AFU or TGF- $\alpha$ & & 91.89 & 100 & 95.38 & 100 & 09.67 & 91.89 \\
\hline AFP, AFU, TGF- $\alpha$ or TGF- $\beta$ & & 97.29 & 100 & 98.46 & 100 & 3.44 & 97.29 \\
\hline At least one marker positive & & 100 & 100 & 100 & 100 & 0 & 100 \\
\hline
\end{tabular}

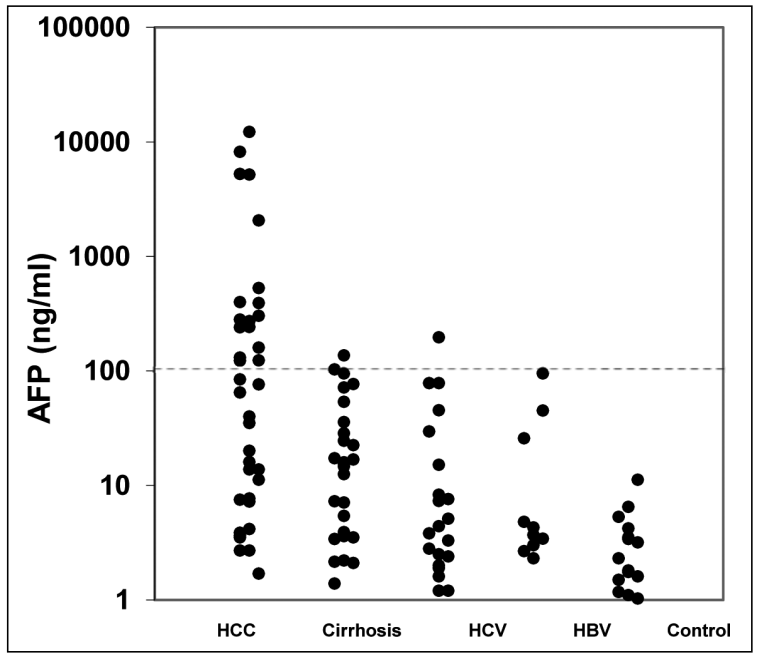

Fig. 1. Scatter diagram of AFP as a diagnostic marker for HCC in cirrhotic population. The horizontal line represents the optimal cut-off $(112.75 \mathrm{ng} / \mathrm{ml})$ at which the sensitivity and specificity are $46 \%$ and $96.4 \%$, respectively.

Receiver operating characteristic (ROC) curves of the markers are shown in Fig. 7. The areas under the ROC curve (AUC) for AFP, AFU, TGF- $\alpha$, TGF- $\beta$ and IL-8 were $0.709,0.853,0.745,0.713$ and 0.708 , respec-

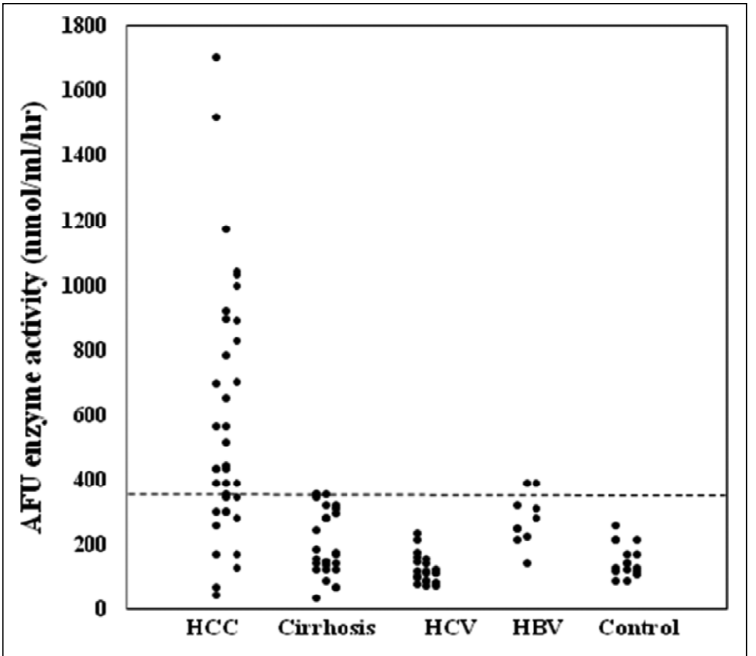

Fig. 2. Scatter diagram of AFU as a diagnostic marker for HCC in cirrhotic population. The horizontal line represents the optimal cut-off $(347.4 \mathrm{u} / \mathrm{l})$ at which the sensitivity and specificity are $72.97 \%$ and $89.28 \%$, respectively.

tively indicating the validity of using all the markers in diagnosis of HCC in cirrhotic population. According to Sox et al. [36], an AUC equal to or greater than 0.7 indicates the acceptance of using a marker in diagnosis. 


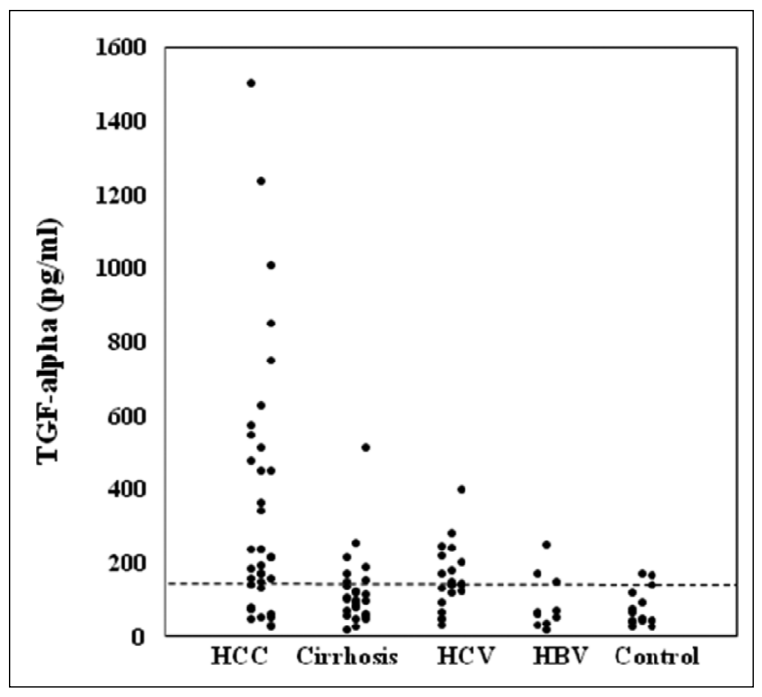

Fig. 3. Scatter diagram of TGF- $\alpha$ as a diagnostic marker for HCC in cirrhotic population. The horizontal line represents the optimal cut-off $(156 \mathrm{pg} / \mathrm{ml})$ at which the sensitivity and specificity are $67.56 \%$ and $82.14 \%$, respectively.

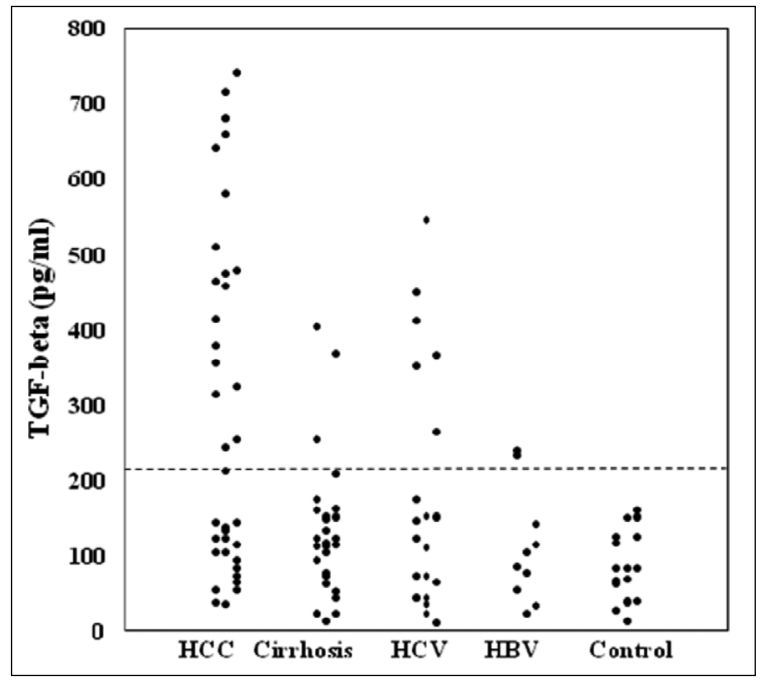

Fig. 4. Scatter diagram of TGF- $\beta$ as a diagnostic marker for HCC in cirrhotic population. The horizontal line represents the optimal cut-off $(212 \mathrm{ng} / \mathrm{ml})$ at which the sensitivity and specificity are $54.05 \%$ and $89.28 \%$, respectively.

\section{Discussion}

HCC generally develops following an orderly progression from cirrhosis to dysplastic nodules to early cancer development, which can be reliably cured if discovered before the development of vascular invasion [37]. Early detection of HCC in those patients provides the best chance for a curative treatment.

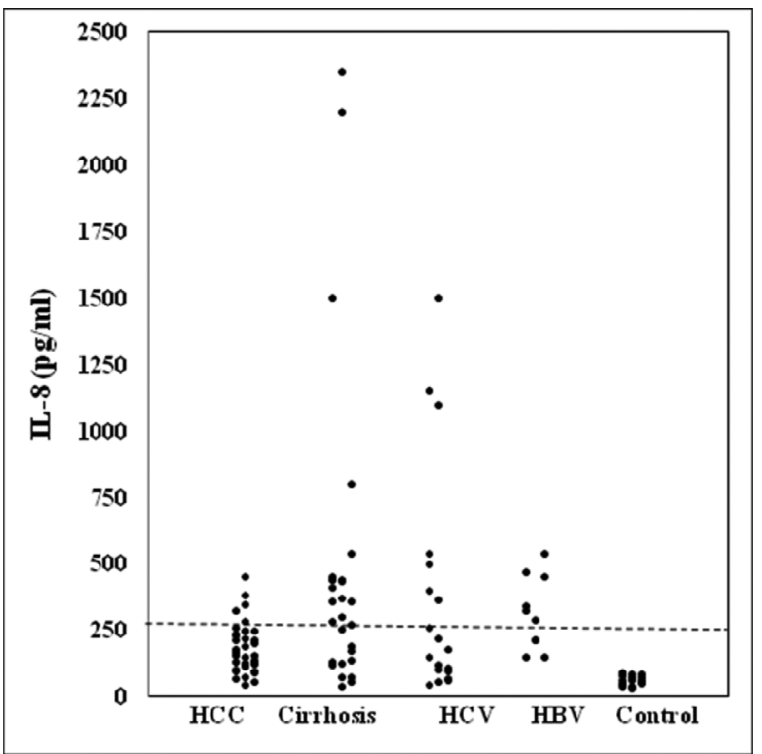

Fig. 5. Scatter diagram of IL-8 as a diagnostic marker for HCC in cirrhotic population. The horizontal line represents the optimal cut-off $(252 \mathrm{pg} / \mathrm{ml})$ at which the sensitivity and specificity are 83.8 $\%$ and $64.3 \%$, respectively.

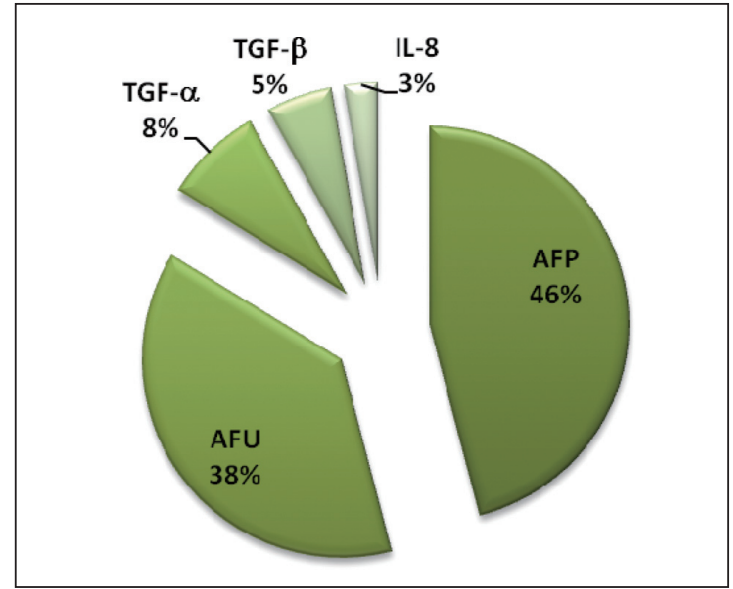

Fig. 6. The build-up in sensitivity due to the combination of data from each of the studied markers.

AFP, the golden marker of HCC, has frequently normal levels in patients with small HCC and moderate levels in a significant proportion of patients with earlystage, potentially curable HCC. Therefore there is an increased need for new tumour markers that may be more sensitive and specific for HCC.

The current study shows significantly higher levels of AFP in patients with HCC than other patients and controls, a finding that came in agreement with the work of many authors $[2,4,5]$. Based on this significant higher 


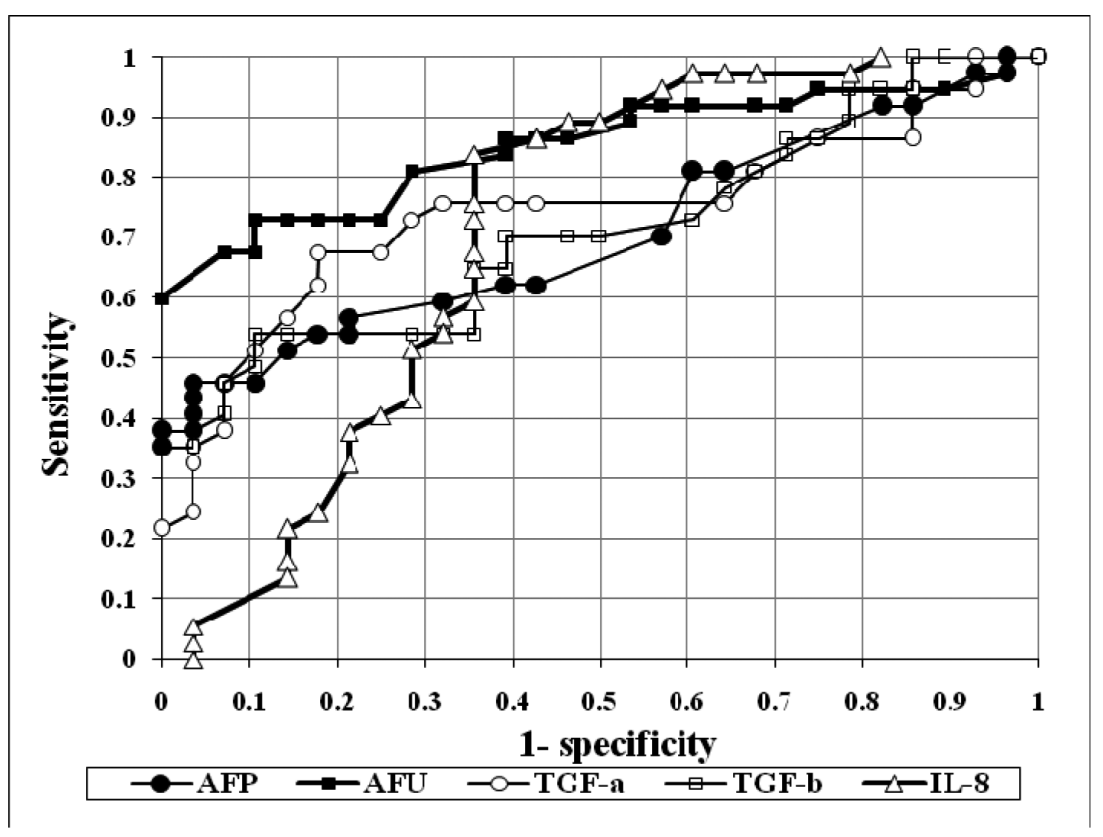

Fig. 7. Receiver operating characteristic (ROC) curves of AFP, AFU, TGF- $\alpha$, TGF- $\beta$ and IL- 8 plotted between the sensitivity representing the true positive rate and 1 -specificity representing the false positive rate. The recorded areas under the curves (AUC) are $0.709,0.853,0.745,0.713$ and 0.708 , respectively indicating the validity of using all of the investigated markers in diagnosis of HCC in cirrhotic patients.

level, an attempt is done to evaluate AFP in diagnosis of HCC using ROC curve analysis [36]. According to the previous authors, the area under the ROC curve (AUC) is used as an indicator for the acceptance or rejection of a marker in diagnosis. The minimal accepted AUC is 0.7 [36]. In the present study, AFP recorded an AUC of 0.709 indicating its validity as a diagnostic marker of HCC in a cirrhotic population. AFP shows low sensitivity (46\%), high specificity $(96 \%)$ and medium diagnostic accuracy (68\%) at the optimal cut-off $(112.75 \mathrm{ng} / \mathrm{ml})$. This means that more than one half of the studied patients with HCC are negative for AFP. This finding came in agreement with El-Houseini et al. [38].

For AFU, a similar behavior is observed where the HCC group shows the highest enzyme activity of all groups and no significant difference can be detected between the other groups and the control. Therefore, its activity may be considered as a valuable marker in HCC detection $[5,13,19]$. The sensitivity of AFU enzyme (73\%) is higher than AFP and the specificity is considerably high $(89 \%)$ with a diagnostic accuracy of $(80 \%)$. This result indicates that AFU can be used as a tumor marker in the diagnosis of HCC if compared with AFP especially in case of low levels of AFP [5]. The AUC for AFU is 0.853 indicating its validity in the detection of HCC and even its superiority over AFP.
A more or less similar results are recorded for both TGF- $\alpha$ (sensitivity $67.5 \%$, specificity $82 \%$ ) and TGF$\beta$ (sensitivity $54 \%$, specificity $89 \%$ ) while for IL- 8 , the sensitivity recorded the highest value $(83.8 \%)$ of all the markers with a specificity of $64.3 \%$ and diagnostic accuracy of $75.4 \%$. With respect to TGF- $\alpha$, the HCC group shows a higher level compared to cirrhosis, HBV and the control groups but not significantly different from the HCV group. The over-expression of TGF- $\alpha$ may be closely correlated with the development, growth or progression of HCC, especially in the livers of patients with chronic hepatitis B [28].

For TGF- $\beta$ the HCC group shows the highest level whereas the other groups are comparable. The overexpression of TGF- $\beta$ in HCC tissues may help to consider it as a marker for progression and prognosis of this malignant tumor [4].

In the present study, the level of serum IL- 8 is markedly elevated in most patients with HCC compared to healthy subjects. This result comes in agreement with Ren et al. [39]. In a previous study, IL-8 is found to be over expressed in the HCC tumor cells compared to the non-tumorous livers [27]. The high serum IL-8 levels in HCC patients may be caused by an excessive production in tumor cells and subsequent release into the circulation.

With respect to the correlation between IL- 8 level and the clinicopathological observations, IL- 8 is pos- 
itively correlated with the tumor size and the tumor stage where IL- 8 level is observed more frequently in patients with tumors $>5 \mathrm{~cm}$ in diameter and advanced tumor stages. These results are in agreement with Ren et al. [39] who suggested that serum IL-8 may be useful in the clinical setting to predict venous invasion and advanced tumor stage.

With respect to the tumor size, TGF- $\beta$ and IL- 8 are significantly correlated to the tumor size where patients with tumor size more than $5 \mathrm{~cm}$ recorded significantly higher values than those with tumor size less than $5 \mathrm{~cm}$. Also Ren et al. [39] observed that IL-8 is more frequent in patients with tumor size more than $5 \mathrm{~cm}$ in diameter. The same markers are also correlated with the stage of the tumor where the tumor level increases as the stage increases.

The simultaneous determination of all of the studied markers increased the sensitivity gradually up to $100 \%$. This suggests that several markers should be used in order to obtain a reliable detection of HCC [38].

\section{Conclusion and recommendations}

The present study proves that the simultaneous determination of the five markers increased the sensitivity of detection of HCC gradually up to $100 \%$. Therefore, it is highly recommended that the patients at risk must be subjected to regular determination of these markers in order to enhance the detection of HCC at an early stage at which the case can be treated before the enlargement of the tumor or its metastasis.

\section{References}

[1] El Serag HB, Davila JA, Petersen NJ, McGlynn KA. The continuing increase in the incidence of hepatocellular carcinoma in the United States: An update. Ann Intern Med, 139: 817-823, 2003.

[2] Gad A, Tanka E, Matsumoto A, Serwah AH, Attia F, Hassan A, Samy A and Ali K. Ethnicity affects the diagnostic validity of alpha-fetoprotein in hepatocellular carcinoma. Asia-Pacific J Clin Oncol, 1(2-3): 64-70, 2005.

[3] Parkin DM, Bray F, Ferlay J, Pisani P. Global cancer statistics, 2002. CA Cancer J Clin, 55: 74-108, 2005.

[4] Abdel Hamid MA. Priority considerations in early laboratory diagnosis of hepatocellular carcinoma. Int J Integrative Biol, 3(3):196-214, 2008.

[5] El-Houseini M, EL-Sherbiny M, Awad MM, Amer MA, Saad AH, and Hussein TD. Serum alpha L-fucosidase enzyme activity as a marker for hepatocellular carcinoma: comparison with AFP using ROC analysis. J Egypt Nat Cancer Inst. 13(4): 277-283, 2001.
[6] Bruix J, Sherman M. Management of hepatocellular carcinoma. Hepatol, 42: 1208-1236, 2005.

[7] Schwartz JD, Schwartz M, Mandeli J, Sung M. Neoadjuvant and adjuvant therapy for resectable hepatocellular carcinoma: Review of the randomized clinical trials. Lancet Oncol,3: 593603, 2002.

[8] Runzhou N, Xiao M, Jin F, Lu C, Huang J and Meng X. Clinical value of hepatoma-specific alpha fetoprotein in the diagnosis of hepatocellular carcinoma. Chinese J Clin Oncol, 3(3): 105-114, 2007.

[9] Jiang Y F, Yang Z H et al. Recurrence or metastasis of HCC: Predictors, early detection and experimental angiogenic therapy. Gastroentrol 6: 61-65, 2002.

[10] Dong ZZ, Yao DF, et al. Clinical impact of plasma TGFbeta 1 and circulating TGF-beta $1 \mathrm{~m}$ RNA in diagnosis of hepatocellular carcinoma. Chinese J Hepatol,15(7): 503-508, 2007.

[11] Wang XH, Qin Y, et al. Dendritic cells pulsed with gp96peptide complexes derived from human hepatocellular carcinoma (HCC) induce specific cytotoxic T lymphocytes. Cancer Immunol. Immunother.54:971-980, 2005.

[12] Zinkin NT, Grall F, et al. Serum proteomics and biomarkers in hepatocellular carcinoma and chronic liver disease. Clin. Cancer Res. 14(2):470-477, 2008.

[13] Ishizuka H, Nakayama T et al. Prediction of the development of hepatocellular carcinoma in patients with liver cirrhosis by the serial determinations of serum $\alpha$-L-fucosidase activity. Intern. Med. 38:927-931, 1999.

[14] Ma J, Gong Q et al. Combined five tumor markers in detecting primary hepatic carcinoma (Chinese with English summary). Zhonghua Wai Ke Za Zhi 38:14-16, 2000.

[15] Yuen MF and Lai CL. Serological markers of liver cancer. Best Prac Res Clin Gastroenterol, 19:91-99, 2005.

[16] Ikoma J, Kaito M, et al. Early diagnosis of hepatocellular carcinoma using a sensitive assay for serum des-gamacarboxy prothrombin: A prospective study. Hepatogastroenterol, 49(4):235-238, 2002.

[17] Malaguarnera G, Giordano M, Paladina I, Berretta M, Cappellani A, Malaguarnera M. Review of serum markers of hepatocellular carcinoma. Dig Dis Sci. 55(10):2744-2755. 2010.

[18] Haydon GH and Hayes PC. Screening for hepatocellular carcinoma. Eur J Gastroenterol Hepatol, 856-860, 1996.

[19] Tangkijvanich P, Tosukhowong P, Bunyongyod P, Lertmaharit $\mathrm{S}$, Hanvivatvong $\mathrm{O}$, Kullavanijaya $\mathrm{P}$ and Poovorawan $\mathrm{Y}$. Alpha-L-fucosidase as a serum marker of hepatocellular carcinoma in Thailand. Southeast Asian J Trop Med Public Health, 30:110-114, 1999.

[20] Grizzi F, Franceschini B, Hamrick C, Frezza EE, Cobos E, Chiriva-Internati $\mathrm{M}$. Usefulness of cancer-testis antigens as biomarkers for the diagnosis and treatment of hepatocellular carcinoma. J Transl Med, 5:3-10, 2007.

[21] Rolfe MW, Kunkel SL, Standiford, TJ, Chensue, SW, Allen, RM, Evanoff HL, Phan S H and Strieter RM. Pulmonary fibroblast expression of interleukin-8: A model for alveolar macrophage derived cytokine networking. Am J Respir Cell Mol Biol, 5: 493-501, 1991.

[22] Adler KB, Fischer BM, Wright D T, Cohn, L A and Becker S. Interactions between respiratory epithelial cells and cytokines: Relationships to lung inflammation. Ann. N. Y. Acad. Sci., 725: 128-145, 1994.

[23] Xie K. Interleukin-8 and human cancer biology. Cytokine Growth Factor Rev., 12: 375-391, 2001.

[24] Singh R K, Gutman M, Radinsky R, Bucana CD and Fidler IJ. Expression of interleukin 8 correlates with the metastatic 
potential of human melanoma cells in nude mice. Cancer Res., 54: 3242-3247, 1994.

[25] Green AR, Green VL, White M C and Speirs V. Expression of cytokine messenger RNA in normal and neoplastic human breast tissue: Identification of interleukin-8 as a potential regulatory factor in breast tumours. Int. J. Cancer, 72: 937-941, 1997.

[26] Miyamoto M, Shimizu Y, Okada K, Kashii Y, Higuchi K, and Watanabe A. Effect of interleukin-8 on production of tumorassociated substances and autocrine growth of human liver and pancreatic cancer cells. Cancer Immunol Immunother 47: 47-57, 1998.

[27] Akiba J, Yano H, Ogasawara S, Higaki K and Kojiro M. Expression and function of interleukin-8 in human hepatocellular carcinoma. Int J Oncol, 18: 257-264, 2001.

[28] Harada K, Shiota G and Kawasaki H. Transforming growth factor-alpha and epidermal growth factor receptor in chronic liver disease and hepatocellular carcinoma. Liver, 19(4):31825, 1999.

[29] Bedossa P, Peltier E, Terris B, Franco D and Poynard T. Transforming growth factor-beta 1 (TGF-beta 1 ) and TGF-beta 1 receptors in normal, cirrhotic, and neoplastic human livers. Hepatol, 21: 760-766,1995.

[30] Tsai JF, Chuang LY, Jeng JE, Yang ML, Chang WY and Hsieh MY. Clinical relevance of transforming growth factor-beta 1 in the urine of patients with hepatocellular carcinoma. Medicine (Baltimore), 76: 213-226, 1997.

[31] Abou-Shady M, Baer HU, Friess H, Berberat P, Zimmermann $\mathrm{A}$, Graber $\mathrm{H}$, et al. Transforming growth factor betas and their signaling receptors in human hepatocellular carcinoma. Am J
Surg, 177: 209-215, 1999.

[32] Fransvea E, Mazzocca A, Antonaci S, Giannelli G. Targeting transforming growth factor (TGF)-beta RI inhibits activation of beta1 integrin and blocks vascular invasion in hepatocellular carcinoma. Hepatol, 9(3):839-850, 2009.

[33] Nejjari M, Hafdi Z, Dumortier J, Bringuier AF, Feldmann G, Scoazec JY. Alpha 6 beta1 integrin expression in hepatocarcinoma cells: Regulation and role in cell adhesion and migration. Int J Cancer, 83: 518-525, 1999.

[34] Giannelli G, Bergamini C, Fransvea E, Sgarra C, Antonaci S. Laminin-5 with transforming growth factor-beta1 induces epithelial to mesenchymal transition in hepatocellular carcinoma. Gastroenterol, 129: 1375-1383, 2005.

[35] Lin Y, Kikuchi S, Obata Y, Yagyu K. Serum levels of transforming growth factor beta1 are significantly correlated with venous invasion in patients with gastric cancer. J Gastroenterol Hepatol, 21: 432-437, 2006.

[36] Sox HC, Blatt MA, Higgins MC and Marton K. Medical decision making. London, Butterworth, pp 67-146, 1989.

[37] Schwartz M, Roayaie S, Konstadoulakis M. Strategies for the management of hepatocellular carcinoma. Nat Clin Pract Oncol 2007, 4:424-432, 2007.

[38] El-Houseini M, Mohammed MS, Elshemey WM, Hussein TD, Desouky OS, and Elsayed AA. Enhanced detection of hepatocellular carcinoma. Cancer control, 12(4): 355-361, 2005.

[39] Ren Y, Tung R, Poon P, Tsui HT, Chen WH, Li Z, Lau C and Yu WC. Interleukin-8 Serum Levels in Patients with Hepatocellular Carcinoma: Correlations with Clinicopathological Features and Prognosis. 9: 5996-6001, 2003. 


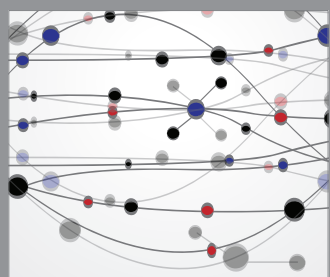

The Scientific World Journal
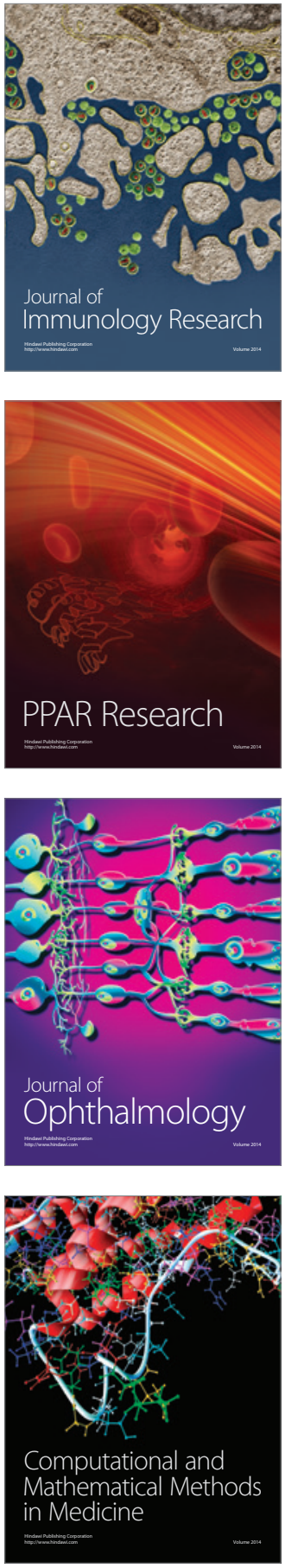

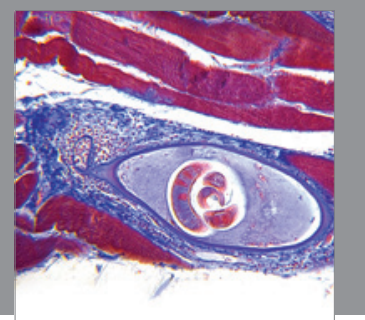

Gastroenterology

Research and Practice
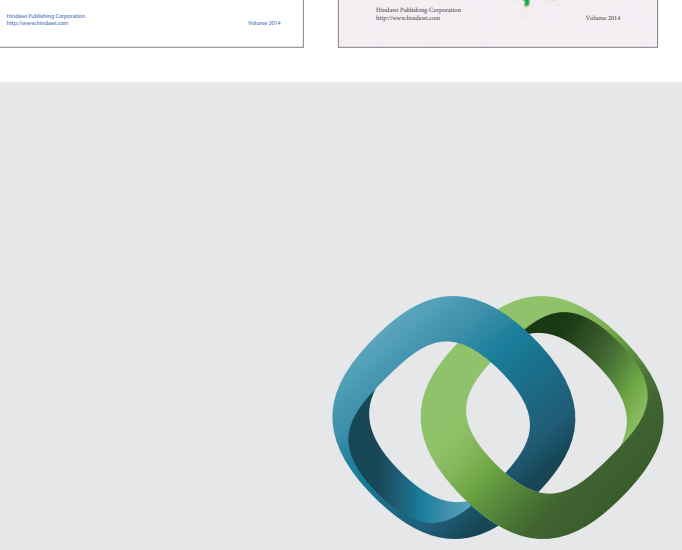

\section{Hindawi}

Submit your manuscripts at

http://www.hindawi.com
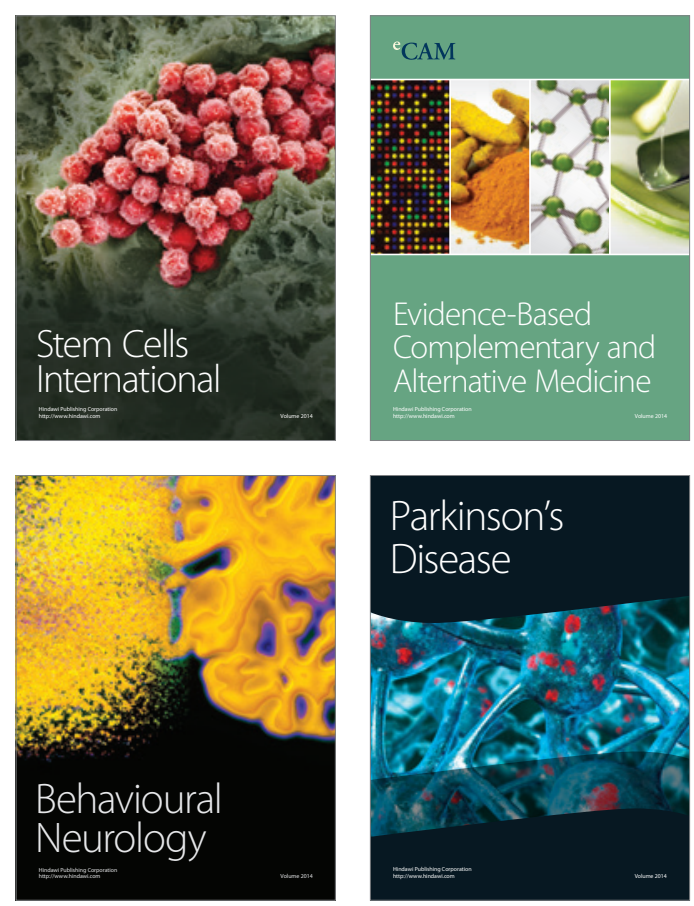

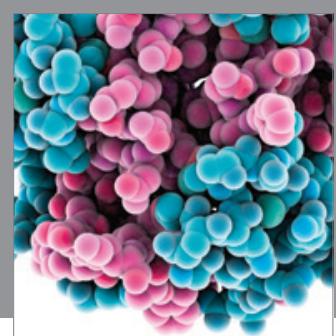

Journal of
Diabetes Research

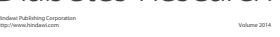

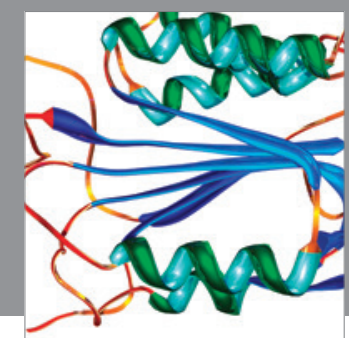

Disease Markers
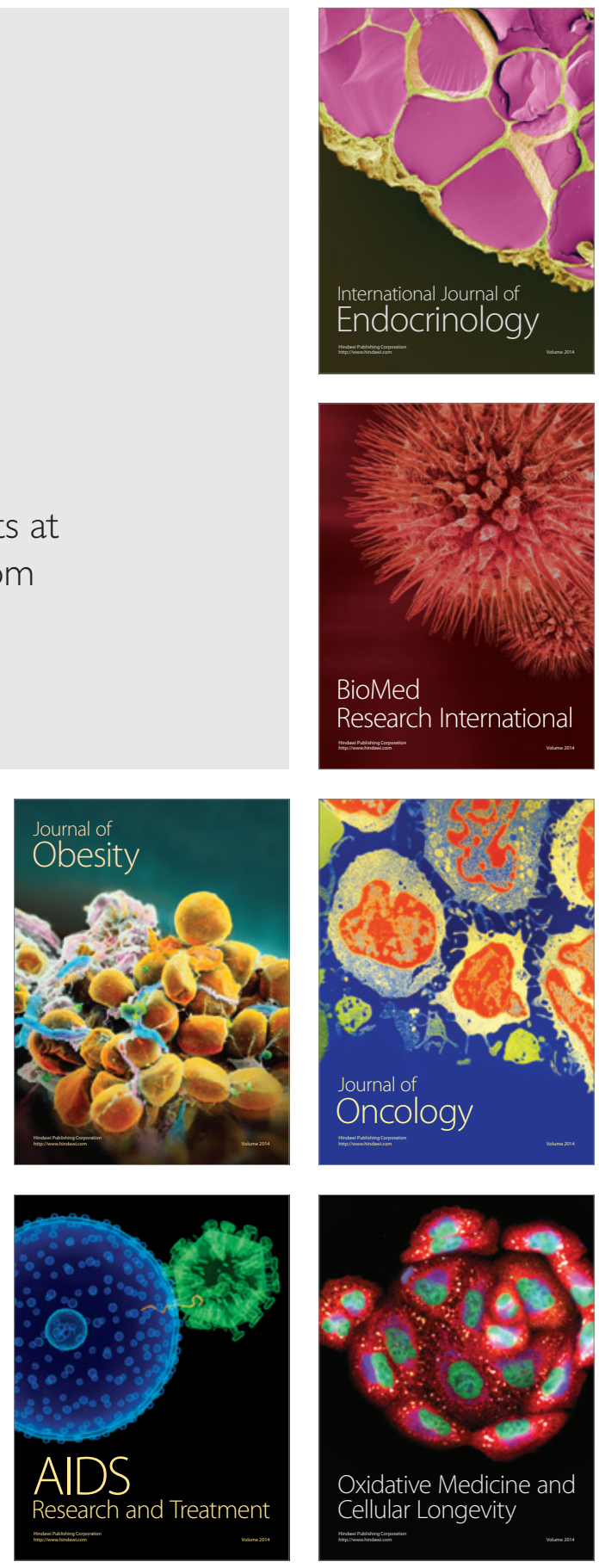